\title{
Prática de atividade física em tempos de pandemia do novo COVID-19: seus benefícios e cuidados
}

https://doi.org/10.11606/issn.1981-4690.v35i2p375-380

\author{
Adriano Alberti* \\ Ben Hur Soares** \\ Leoberto Ricardo Grigollo ${ }^{* * * *}$ \\ Adriano Pasqualotti** \\ Eliane Traebert* \\ Clarissa Martinelli Comim* \\ Rudy J osé Nodari J únior ${ }^{* * * *}$ \\ Fabiana Schuelter-Trevisol ${ }^{* * * *}$
}

*Universidade do Sul de Santa Catarina

Palhoça, SC, Brasil.

**Universidade de

Passo Fundo, Passo

Fundo, RS, Brasil.

***Universidade

do Oeste de Santa

Catarina, Joaçaba,

SC, Brasil.

****Salus Dermatoglifia, Joaçaba, SC, Brasil.

$* * * * *$ Universidade do

Sul de Santa Catarina,

Tubarão, SC, Brasil.

\section{Resumo}

A COVID-19 surgiu no final do ano de 2019 na China. Trata-se de uma doença infecciosa causada por coronavírus da síndrome respiratória aguda grave 2 (SARS-CoV-2). A doença se espalhou rapidamente pelo mundo e causou colapso nos sistemas de saúde de diversos países. Uma das poucas medidas eficazes para conter seu avanço, enquanto não surgem vacinas, é o distanciamento social. No entanto isso tem causado mais sedentarismo e consumo energético excessivo, pelo confinamento em casa e pela ansiedade gerada pela própria pandemia, aumentando o risco de obesidade e ocorrência de doenças crônicas não transmissiveis, ou seu agravamento. A prática de atividade física pode prevenir o surgimento dessas doenças, além de ser um grande aliado na prevenção e tratamento de diversas doenças do trato respiratório. Contudo, a prática de atividade física torna-se um desafio entre seguir os protocolos e recomendações das autoridades sanitárias, o que pode influenciar no rendimento físico. Este estudo, por meio de uma revisão da literatura, pontua sobre os benefícios que a prática de atividades físicas pode trazer às pessoas em relação a pandemia de COVID-19 e os cuidados que devem ser tomados para sua prática mais segura.

Palavras-chave: Atividade física; COVID-19; Pandemia.

\section{Introdução}

No início de dezembro de 2019, surgiu em Wuhan, Província de Hubei, China, casos de pneumonia de etiologia desconhecida, com potencial de disseminação internacional. Cientistas chineses isolaram e mapearam geneticamente o vírus das secreçóes de um paciente acometido, e posteriormente a OMS o nominou de SARS-CoV-2, um novo tipo de coronavírus, causador da COVID-19 $9^{1,2}$.

O coronavírus é um agente etiológico conhecido por causar infecçóes respiratórias, gastrointestinais, hepáticas e de sistema nervoso central entre humanos e diversos animais. No passado, houve incidentes envolvendo outros tipos de coronavírus: surtos de síndrome respiratória aguda grave (SARS-CoV) entre
2002/2003 e síndrome respiratória do Oriente Médio (Mers-CoV) em 2012. Inicialmente o SARS-CoV-2 pareceu ser menos agressivo e com menor taxa de letalidade do que SARS-CoV e Mers-CoV ${ }^{3}$.

A proteína spike se se liga ao receptor da enzima conversora de angiotensina 2 e ativa a replicação viral. Este processo danifica a célula hospedeira e causa a prioptose por danos causados por ATP, ácidos nucleicos e oligômeros ASC. As células vizinhas do endotélio reconhecem as alteraçôes, presença de macrófagos alveolares e células endoteliais que desencadeiam a geração de citocinas e quimiocinas pro-inflamatórias (IL-6, IP-10, MIP-1 $\alpha$, MIP-1 $\beta$ e MPC-1, que atraem macrófagos, células T, INT $\gamma$ 
criando um loop de feedback proinflamatório. $\mathrm{Na}$ produção de anticorpos neutralizantes a infecção se resolve; mas pode haver produçáo de anticorpos náo neutralizantes gerando uma tempestade de citocinas. Essa resposta inflamatória inadequada e exacerbada permite que a viremia ocasionando um quadro de sepse e dano em outras células alvo de órgãos vitais como pulmão, coração, rins e fígado. A gravidade tende a acometer idosos e pessoas com comorbidades e fatores de risco, provavelmente por baixa imunogenicidade. Ademais, pacientes diabéticos e hipertensos possuem mais receptores ECA-2-2-4.

Para conter a rápida disseminação do vírus, medidas de restriçáo de contato social e quarentena, ampla divulgação sobre o novo coronavírus, tanto em relação à aspectos epidemiológicos, quanto preventivos, foram implementadas em diversos países. Algumas medidas foram adotadas mais precocemente, e outras mais tardiamente, o que resultou em desfechos desiguais com maior ou menor número de infectados e vítimas fatais. O isolamento social é a melhor maneira de conter seu progresso, achatando a curva epidemiológica para evitar colapsos no sistema de saúde e, consequentemente, salvar vidas 5 .

No entanto, essa mudança no comportamento do estilo de vida levou as pessoas a adotarem um estilo de vida mais sedentário, aumentando o risco de desenvolver outras doenças ou exacerbar as doenças crônicas existentes que poderiam ser evitadas pela atividade física.

\section{Pandemia de Covid-19}

Desde dezembro de 2019, a nova infecção por Coronavírus mostra as características epidemiológicas clínicas da disseminação rápida e a capacidade de infectar uma população em geral suscetível. $\mathrm{O}$ agente patogênico pertence à Coronavírus de tipo $\beta$, é uma doença altamente infecciosa, e o surto em andamento foi declarado pela OMS como uma emergência global de saúde pública ${ }^{6,7}$.

Em pouco tempo foi possível perceber uma contaminação propagada em uma aceleração maior que a possibilidade de cura de cada um dos casos, no entanto, muitos outros casos apresentavam-se de maneira não identificada, gerando um risco elevado de disseminação ${ }^{8}$.

A fração de casos não documentados, mas infecciosos, é uma característica epidemiológica crítica que modula o potencial pandêmico de um vírus respiratório emergente ${ }^{9,10}$. Essas infecçóes indocumentadas, geralmente apresentam sintomas leves e limitados, portanto, passam despercebidos, e pendentes em sua contagiosidade e números, expondo uma parcela muito maior da população ao vírus do que de outra forma ${ }^{8}$.

A transmissão, ocorre principalmente com o contato de gotículas respiratórias, oriundas de pacientes contaminados, e a doença afeta principalmente os sistemas respiratório, cardiovascular, gastrointestinal e neurológico ${ }^{8,11}$. Pode-se apresentar desde a forma assintomática até formas graves, com importante comprometimento do sistema respiratório. Seu cortejo sintomatológico é composto principalmente por febre, tosse seca e dispneia, com possibilidade de complicaçóes, principalmente pneumonia, síndrome respiratória aguda grave (SRAG) e óbito ${ }^{4,12}$. Trata-se de uma doença complexa e com poucas evidências da melhor forma de tratamento ${ }^{4}$.

\section{Benefícios da pratica de atividade física em relação a Covid-19}

A prática de atividade física traz inúmeros benefícios para a saúde das pessoas, independente da idade, sendo em pleno século XXI um meio para a promoção da saúde. Mas devido a pandemia do COVID-19 foi necessário ser realizado o distanciamento social e em diversos casos a única alternativa comprovada cientificamente que poderia achatar a curva de contaminaçáo foi o fechamento total dos estabelecimentos, incluindo o fechamento de academias de ginástica, parques, playgrounds e demais instalaçóes de recreaçáo, sendo que consequentemente essas praticas aumentaram o comportamento sedentário da população ${ }^{13}$.

O comportamento sedentário aumenta as chances de desenvolvimento de doenças crônicas, mas apesar desse cenário é possível ser realizado a prática da atividade física. À medida que o trabalho em casa se torna predominante, as oportunidades de se envolver em estilos de vida flexíveis podem permitir oportunidades para incorporar mais naturalmente a atividade física na vida diária ${ }^{14}$.

A prática de atividade física pode impedir o desenvolvimento da SARA (Síndrome da Angústia Respiratória Aguda), caracterizada pela falta de ar, respiração rápida, tosse, fraqueza muscular, sendo uma das piores complicações do COVID-19. Além de que, a prática de atividade física eleva a produção da enzima superóxido dismutase (EcSOD) que é produzida pelos músculos e está associada a proteção do sistema cardiorrespiratório ${ }^{14}$. 


\section{Cuidados com a prática de atividade física em tempos de Covid-19}

Apesar dos benefícios que a prática de atividade física traz, é necessário cuidados em sua realização em meio a uma pandemia, pois se não tomado os devidos cuidados pode-se contribuir para a transmissão da COVID-19, sendo assim, é importante respeitar as medidas de prevenção e controle $^{15} \mathrm{O}$ profissional de educaçáo física pode acompanhar esses sintomas em seus alunos para garantir que eles possam se exercitar com segurança. Nyenhuis et al. ${ }^{16}$ destaca a importância da atividade física e recomenda que os pacientes permaneçam ativos em casa durante esse período de isolamento social, mas respeitando os devidos cuidados de prevenção e controle.

Mesmo sabendo que o distanciamento é um método mais eficaz para reduzir o contágio do Coronavírus, nem sempre é possível ficar isolado $100 \%$. A necessidade de deslocamento para o mercado, farmácia, bancos entre outros, denominados como essenciais, ou no caso de algumas pessoas que náo podem optar pelo home office, acabam se expondo de alguma forma ao contágio.

A prática de atividade física, eventos culturais e esportivos, bem como os encontros sociais foram citados nos diferentes decretos publicados nos mais diversos países, restringindo, e em alguns casos criando e em alguns casos criando flexibilização a prática, sendo que os ambientes fechados como academias as restriçôes foram mais pontuais ${ }^{17}$

Também se reconhece que existem coortes de atletas e para-atletas com maior suscetibilidade à infecção viral do trato respiratório e coortes com condiçóes médicas crônicas conhecidas, como doença das vias aéreas (observada em aproximadamente $20 \%$ de todos os atletas de resistência) ${ }^{18}$.

A retomada das atividades físicas em grupos ou locais fechados deve ser discutida com cautela para a sua retomada mais segura possível, pois a disseminação do COVID-19 pode ocorrer efetivamente por meio de saliva, geralmente sob a forma de micro gotículas Quando uma pessoa espirra, tosse ou até exala, está emitindo gotículas pequenas - geralmente pequenas demais para serem vistas a olho nu - que podem transmitir o vírus. As pessoas receptoras podem ser infectadas inalando essas gotículas ou colocando-as nas mãos e tocandoas no rosto. Devido isso a OMS e os países em todo mundo estabeleceram uma distancia de 1,5 metros a ser mantida entre as pessoas ${ }^{2,19}$.
Essa medida é considerada importante e eficaz porque as gotículas devem cair no cháo ou evaporarse antes de viajar uma distancia de 1,5 metros. No entanto essa distância foi determinada para pessoas que estáo paradas. Isso não leva em consideração os potenciais efeitos aerodinâmicos introduzidos pelo movimento de pessoas, como caminhar rápido, corrida e ciclismo ${ }^{19}$.

Em um estudo realizado por BLOCKEN et al. ${ }^{19}$ os resultados indicaram que a pessoa fica muito mais exposta as gotículas expelidas por uma pessoa que está a frente caminhando ou correndo, mesmo que em uma distancia de 1,5 metros, esse mesmo estudo aponta que há risco potencial em determinadas distâncias e modalidades:

- Caminhada: simulação aponta risco quando a distância é inferior a entre 4 e 5 metros da pessoa que está à sua frente;

- Corrida: simulaçáo aponta risco quando a distância é inferior a pelo menos 10 metros da pessoa que está à sua frente;

- Pedalada: simulação aponta risco quando a distância é inferior a pelo menos 20 metros da pessoa que está à sua frente.

$\mathrm{KALU}^{18}$ ressalta que para atletas e clínicos preocupados com sua saúde, é importante que haja orientaçóes direcionadas para garantir o bem-estar dessa população. $\mathrm{O}$ risco aumentado de transmissão do COVID-19 durante o treinamento é mais provável em certos ambientes atléticos, onde os atletas treinam em grupos, praticam esportes de contato, não aderem às diretrizes universais de distanciamento social, fazem uso de equipamentos compartilhados, não praticam diretrizes universais para manter higiene pessoal e usar instalaçóes comuns, como vestiários. No entanto, não existem dados específicos disponíveis sobre a prevalência, natureza e comportamento da doença relacionada ao COVID-19 em indivíduos atléticos ${ }^{18}$.

Medidas de distanciamento social, foram adotadas com o objetivo de reduçáo do número de pessoas nos mais diferentes locais, se tornando uma realidade em diversas partes do mundo. Junto com o uso da máscara, manter-se afastado dos outros é um dos principais meios de reduzir os riscos de transmissão do vírus, mantendo ainda o distanciamento entre as pessoas de pelo menos 1,5 metros, o afastamento social pode ser ainda mais eficaz a cada centímetro adicionado nesta conta ${ }^{20}$. Além do distanciamento, o outro resultado obtido pode confirmar a importância do uso da máscara de proteção. Um estudo realizado por DereK et 
$\mathrm{al}^{20}$, demonstrou que quando alguém fica a menos de 1,5 metros de distância de outra pessoa, o risco de contaminação sobe para $17 \%$. Porém, se ambas estiverem usando máscaras, esse número pode diminuir para $3 \%$.

Segundo Blocken et al. ${ }^{19}$ o uso de máscaras durante a atividade física é fundamental para que as gotículas sejam contidas, diminuindo a sua propagação, sendo assim, o uso de mascaras é de extrema importância também durante a pratica de atividades físicas para que diminua as chances de contagio da COVID-19.

Baseado nestas evidências o uso da máscara se popularizou na rotina de milhares de pessoas em todo o país, como medida de segurança para conter o avanço do Coronavírus. A máscara cria uma barreira física que impede a proliferação do vírus, ajudando a reduzir o número de pessoas infectadas ${ }^{21}$. Os autores lembram ainda, que a máscara deve ser confeccionada do material de tecido, possuir no mínimo uma camada interna e uma camada externa e obrigatoriamente um elemento filtrante, e lembrar de afixar corretamente a máscara sobre o nariz, deixando um mínimo de espaço, lembra-se ainda que as máscaras devem ser trocadas a cada 2 horas ou quando apresentarem sinais de umidade.

Para os praticantes de todas as modalidades esportivas, o uso de máscaras pode funcionar como um importante recurso para diminuir a exposição e o risco de contaminação. O Coronavírus é espalhado por gotículas expelidas por pessoas contaminadas quando conversam, tossem ou espirram, e em atividades esportivas, devido ao aumento ventilatório, as gotículas passam a ser expelidas em volumes maiores, aumentando o risco de contaminação, assim, as máscaras atuam como barreira física para reduzir a formação de gotículas ${ }^{21}$.

A prática de atividade física e exercícios que oscilam de baixa a alta intensidade, necessitam

\section{Considerações Finais}

A prática de atividade física deve ser realizada, pois previne o surgimento de doenças crônicas não transmissíveis, ou seu agravamento, porém seguindo as medidas de proteçấo para não propagação do COVID-19, deve-se também ficar atento a intensidade diretamente da absorção do oxigênio. Quando o praticante passa a ter uma restrição na captação de oxigênio e outras variáveis ventilatórias, sofrem uma absorção diminuída ou restritiva de oxigênio, a atividade realizada, sofre uma atenuação em seu desempenho ${ }^{22}$.

Vale reforçar que com o uso das máscaras, a boca e o nariz do praticante, encontra-se ou se estiverem totalmente cobertos, pode haver alguma limitação à ingestão de ar, no transcorrer dos exercícios, e consequentemente uma absorção menor de oxigênio, esta restriçáo promove um desconforto fisiológico, exigindo que sejam reduzidos o volume e ou a intensidade das dinâmicas em execução, gerando um grau de hipóxia, que significa baixo teor (concentraçáo) de oxigênio. A aplicação de hipóxia em sessão de treinamento de atletas também apresenta benefícios, mostrando aumento de força, resistência e aumento do tamanho muscular ${ }^{23,24}$, podendo ser benéficos durante altas cargas de treinamento, em temporadas competitivas ou em reabilitação $0^{23,25}$.

Alguns estudos investigaram seus efeitos relacionados ao exercício ${ }^{26-28}$. Dentre esses estudos, somente Granados et al. ${ }^{26}$ e Porcari et al. ${ }^{28}$ avaliaram a saturação de oxigênio $(\mathrm{SaO} 2)$, um importante variável para descrever hipóxia, analisada de forma indireta por oxímetro de pulso. Porcari et al. ${ }^{28}$ verificou, em estudo crônico em cicloergomêtro que o uso de máscaras de altitude, propiciou maior queda de $\mathrm{SaO} 2(93.2 \%)$ em relação ao grupo controle (sem máscaras) (95.8\%) durante sessóes de treino. Apesar de estes achados serem interessantes para o conhecimento dos efeitos da restrição do fluxo de ar, ainda se restringem a protocolos fundamentalmente de treinamento aeróbio e adaptaçóes relacionadas ao sistema cardiorrespiratório, sendo os efeitos da restrição de ar.

do exercício, pois o uso de mascaras pode causar limitação à ingestão de ar e consequentemente uma absorção menor de oxigênio, esta restrição promove um desconforto fisiológico, exigindo que sejam reduzidos o volume e ou a intensidade da atividade física. 


\begin{abstract}
Physical activity during the Covid-19 pandemic: benefits and precautions

Coronavirus disease 2019 (COVID-19) emerged at the end of 2019 in China. It is an infectious disease caused by the severe acute respiratory syndrome coronavirus 2 . The disease spread rapidly around the world and caused the collapse of health systems in several countries. As a vaccine is not available, one of the few effective measures to curb its advancement is social distancing. However, this has led to an increased sedentary lifestyle and excessive energy consumption as a result of home confinement and the anxiety generated by the pandemic itself, increasing the risk of obesity and the occurrence of chronic non-communicable diseases, or their worsening. The practice of physical activity can prevent the onset of these diseases, besides being great ally in the prevention and treatment of several diseases of the respiratory tract. However, the practice of physical activity becomes a challenge between following the protocols and recommendations from the health authorities. This study, through a literature review, lists the benefits that the practice of physical activities can bring to individuals during the COVID-19 pandemic.
\end{abstract}

KeYwords: Physical activity; COVID-19; Pandemic.

\title{
Referências
}

1. Bogoch II, Watts A, Thomas-Bachli A, Huber C, Kraemer MUG, Khan K. Pneumonia of unknown aetiology in Wuhan, China: potential for international spread via commercial air travel. J Travel Med. 2020;27(2).

2. World Health Organization. Emergencies. Diseases. Coronavirus disease 2019 (COVID-2019) pandemic. Disponível em: https://www.who.int/emergencies/diseases/novel-coronavirus-2019.

3. Chen P, Ma L, Nassis GP, Harmer P, Ainsworth BE, Li F. Coronavirus disease (COVID-19): the need to maintain regular physical activity while taking precautions. J Sport Health Sci. 2020;9:103-104.

4. Hellewell J, Abbott S, Gimma A, Bosse NI, Jarvis CI, Russel TW, et al. Feasibility of controlling COVID-19 outbreaks by isolation of cases and contacts. Lancet Glob Health. 2020;8:e488-96.

5. Fergunson NM, Laydon D, Nedjati-Gilani G, Imai N, Ainslie K, Baguelin M, et al. Impact of non-pharmaceutical intervantions (NPIs) to reduce COVID-19 mortality and healthcare demand. MRC Centre for Global Infectious Disease Analysis. Scientific Advisory Group for Emergencies, 2020.

6. Zhu N, Zhang D, Wang W. Um novo coronavírus de pacientes com pneumonia na China, 2019. N Engl J Med. 2020.

7. Huang C, Wang Y, Li X. Características clínicas de pacientes infectados com o novo coronavírus de 2019 em Wuhan, China. Lancet. 2020.

8. Li R, Pei S, Chen B, Song Y, Zhang T, Yang W, Shaman J. Substantial undocumented infection facilitates the rapid dissemination of novel coronavirus (SARS-CoV2). Science. 2020. Disponível em: 10.1126/science.abb3221

9. Chan JF, Yuan S, Kok KH, To KK, et al. A familial cluster of pneumonia associated with the 2019 novel coronavirus indicating person-to-person transmission: a study of a family cluster. Lancet. 2020;395:514-52.

10. Du Z, Wang L, Cauchemez S, Xu X, et al. Risk for transportation of 2019 novel coronavirus disease from Wuhan to other cities in China. Emerg Infect Dis. 2020;26.

11. Perlman S. Another decade, another coronavirus. N Engl J Med. 2020. Acesso em: 27 fev 2020. Disponível em: https:// doi.org/10.1056/NEJM200126.

12. Wang D, Hu BHUC, Zhu F, Liu X, et al. Clinical Characteristics of 138 Hospitalized Patients With 2019 Novel Coronavirus-Infected Pneumonia in Wuhan, China. JAMA. 2020.

13. Lesser IA, Nienhuis CP. The impact of COVID-19 on physical activity behavior and well-being of canadians. Int J Environ Res Public Health. 2020;17(11).

14. Yan Z, Spaulding HR. Extracellular superoxide dismutase, a molecular transducer of health benefits of exercise. Redox Biol. 2020.

15. Ahmed I. COVID-19 - does exercise prescription and maximal oxygen uptake (VO2 max) have a role in risk-stratifying patients? Clinical Medicine (Northfield Il). 2020;23:282.

Rev Bras Educ Fís Esporte, (São Paulo) 2021 Abr-Jun;35(2):375-380 • 379 
16. Nyenhuis SM, Greiwe J, Zeiger JS, Nanda A, Cooke A. Exercise and Fitness in the age of social distancing during the COVID-19 Pandemic. J Allergy Clin Immunol Pract. 2020;8(7):2152-2155.

17. Parnell D, Widdop P, Bond A, Wilson R. COVID-19, networks and sport. Manag Sport Leisure. 2020. Disponível em: https://doi.org/10.1080/23750472. 2020.1750100

18. Hull JH, Loosemore M, Schwellnus M. Resoiratory health in athletes: facing the Covid-19 challenge. Lancet Respir Med. 2020;8(6):557-558. Disponível em: https://doi.org/10.1016/ S2213-2600(20)30175-2

19. Blocken B, Malizia F, van Druenen T, et al. Towards aerodynamically equivalent COVID19 $1.5 \mathrm{~m}$ social distancing for walking and running. [Preprint]. Disponível em: http://www.urbanphysics.net/Social\%20Distancing\%20v20_ White_Paper.pdf (2020).

20. Derek KC, Elie A, Stephanie D, Karla S, Sally Y, Holger JS. Physical distancing, face masks, and eye protection to prevent person-to-person transmission of SARS-CoV-2 and COVID-19: a systematic review and meta-analysis. Lancet. 2020;395(10242):1973-1987.

21. De Checchi, Ribeiro MH. Guia de segurança para profissionais atuantes na atenção primária à saúde durante a pandemia de COVID - 19. Coari, AM: Universidade Federal do Amazonas, 2020.

22. Tanimoto M, Madarame H, Ishii N. Muscle oxygenation and plasma growth hormone concentration during and after resistance exercise: Comparison between "KAATSU” and other types of regimen. Int J KAATSU Training Res. 2005;1(2):51-6.

23. Cook SB, Murphy BG, Labarbera KE. Neuromuscular function after a bout of low-load blood flow-restricted exercise. Med Sci Sports Exerc. 2013;45(1):67-74.

24. Takarada Y, Sato Y, Ishii N. Effects of resistance exercise combined with vascular occlusion on muscle function in athletes. Eur J Appl Physiol. 2002;86(4):308-14

25. Scott BR, Slattery KM, Sculley DV, Hodson JA, Dascombe BJ. Physical performance during high-intensity resistance exercise in normoxic and hypoxic conditions. J Strength Cond Res. 2015;29(3):807-15.

26. Granados J, Gillum TL, Castillo W, Kevin M, et al. Functional respiratory muscle training during endurance exercise causes modest hypoxemia but overall Is well tolerated. J Strength Cond Res. 2016;30(3):755-762.

27. Motoyama YL, Joel GB, Pereira PEA, Esteves GJ, Azevedo PHSM. Airflow-restricting mask reduces acute performance in resistance exercise. Sports. 2016;4(4):46.

28. Porcari JP, Probst L, Forrester K, Doberstein S, Foster C, Cress ML, Schmidt K. Effect of wearing the elevation training mask on aerobic capacity, lung function, and hematological variables. J Sports Sci Med. 2016;15(2):379.

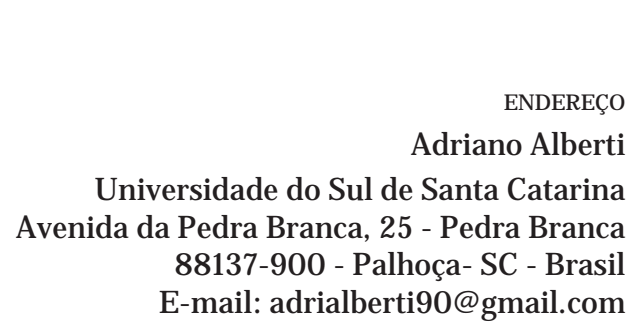

Submetido: 01/09/2020

Aceito: 23/02/2021

380 • Rev Bras Educ Fís Esporte, (São Paulo) 2021Abr-J un;35(2)375-380 